\title{
Alterations in regulation of energy homeostasis in cyclic nucleotide phosphodiesterase 3B-null mice
}

\author{
Young Hun Choi, ${ }^{1}$ Sunhee Park, ${ }^{1}$ Steven Hockman, ${ }^{1}$ Emilia Zmuda-Trzebiatowska, ${ }^{2}$ \\ Fredrik Svennelid, ${ }^{2}$ Martin Haluzik, ${ }^{3}$ Oksana Gavrilova, ${ }^{3}$ Faiyaz Ahmad, ${ }^{1}$ \\ Laurent Pepin, ${ }^{1}$ Maria Napolitano, ${ }^{1}$ Masato Taira, ${ }^{1}$ Frank Sundler, ${ }^{2}$ \\ Lena Stenson Holst, ${ }^{2}$ Eva Degerman, ${ }^{2}$ and Vincent C. Manganiello'
}

${ }_{1}^{1}$ Pulmonary-Critical Care Medicine Branch (PCCMB), National Heart, Lung, and Blood Institute (NHLBI), NIH, Bethesda, Maryland, USA. 2Department of Experimental Medical Science, Lund University, Lund, Sweden. ${ }^{3}$ Diabetes Branch, NIDDK, NIH, Bethesda, Maryland, USA.

Cyclic nucleotide phosphodiesterase 3B (PDE3B) has been suggested to be critical for mediating insulin/ IGF-1 inhibition of cAMP signaling in adipocytes, liver, and pancreatic $\beta$ cells. In Pde $3 b$-KO adipocytes we found decreased adipocyte size, unchanged insulin-stimulated phosphorylation of protein kinase $B$ and activation of glucose uptake, enhanced catecholamine-stimulated lipolysis and insulin-stimulated lipogenesis, and blocked insulin inhibition of catecholamine-stimulated lipolysis. Glucose, alone or in combination with glucagon-like peptide-1, increased insulin secretion more in isolated pancreatic KO islets, although islet size and morphology and immunoreactive insulin and glucagon levels were unchanged. The $\beta_{3}$-adrenergic agonist CL 316,243 (CL) increased lipolysis and serum insulin more in $\mathrm{KO}$ mice, but blood glucose reduction was less in CL-treated $\mathrm{KO}$ mice. Insulin resistance was observed in $\mathrm{KO}$ mice, with liver an important site of alterations in insulin-sensitive glucose production. In KO mice, liver triglyceride and cAMP contents were increased, and the liver content and phosphorylation states of several insulin signaling, gluconeogenic, and inflammation- and stress-related components were altered. Thus, PDE3B may be important in regulating certain cAMP signaling pathways, including lipolysis, insulin-induced antilipolysis, and cAMP-mediated insulin secretion. Altered expression and/or regulation of PDE3B may contribute to metabolic dysregulation, including systemic insulin resistance.

\section{Introduction}

cAMP plays critical roles in regulating energy metabolism. For example, the rate of triglyceride (TG) hydrolysis (lipolysis) is dependent on intracellular cAMP, and cAMP signaling pathways also modulate gluconeogenesis, glycogenolysis, insulin secretion, and thermogenesis (1). By catalyzing hydrolysis of cAMP and cGMP, cyclic nucleotide phosphodiesterases (PDEs) regulate their intracellular concentrations and, consequently, their physiological effects. PDEs belong to a complex and diverse superfamily of at least 11 structurally related, highly regulated, and functionally distinct gene families (PDE1-PDE11) $(2,3)$.

Two PDE3 subfamilies, PDE3A and PDE3B, are products of separate, but homologous, genes $(3,4)$ and exhibit different patterns of expression. PDE3A is relatively more abundant in the cardiovascular system, and PDE3B in cells of importance for energy metabolism including hepatocytes, brown and white adipocytes, and pancreatic $\beta$ cells $(4,5)$. PDE3B is also found in the

Nonstandard abbreviations used: CL, CL 316,243; CREB, cAMP regulatory element-binding protein; Cyc, cyclophilin A; EGP, endogenous glucose production; FAS, fatty acid synthase; FKHRL1, Forkhead (Drosophila) homolog (rhabdomyosarcoma) like 1; GLP-1, glucagon-like peptide-1; GSK-3, glycogen synthase kinase-3; GTT, glucose tolerance test; HE, heterozygous; IRS-1, insulin receptor substrate-1; ISO, isoproterenol; ITT, insulin tolerance test; $\mathrm{Neo}^{\mathrm{r}}$, neomycin resistance; PAI-1, plasminogen activator inhibitor-1; PDE, cyclic nucleotide phosphodiesterase; PEPCK, phosphoenolpyruvate carboxykinase; PGC- $1 \alpha$, PPAR $\gamma$ coactivator- $1 \alpha$; TRB3, tribbles 3 ; TG, triglyceride

Conflict of interest: The authors have declared that no conflict of interest exists. Citation for this article: J. Clin. Invest. 116:3240-3251 (2006). doi:10.1172/JCI24867. cardiovascular system (6). One characteristic of PDE3B isoforms is their activation in response to insulin, IGF-1, and leptin via PI3K-dependent signals as well as to agents that increase cAMP (7). In adipocytes, activation of PDE3B is thought to be a major mechanism whereby insulin increases degradation of cAMP and antagonizes catecholamine-induced lipolysis (7). PDE3B is also apparently involved in regulation of insulin-induced glucose uptake, glucose transporter-4 (GLUT-4) translocation, and lipogenesis $(8,9)$. IGF-1- (5), leptin- $(10,11)$, and insulin-mediated (11) activation of PDE3B may be important in inhibition of cAMP-induced glycogenolysis in hepatocytes (11) and of cAMPstimulated secretion of insulin from pancreatic $\beta$ cells $(5,10)$. Furthermore, overexpression of PDE3B in pancreatic $\beta$ cells, both in vivo and in vitro, antagonized glucose- and glucagonlike peptide-1-mediated (GLP-1-mediated) increases in cAMP accumulation and insulin secretion $(12,13)$.

Although mechanisms for acute activation of PDE3B and its potential physiological role(s) have been extensively studied in cultured cells, its role(s) in human and animal physiology or in the development of dysregulated metabolic states, including systemic insulin resistance, is not well understood. In some rodent diabetes models, PDE3B expression is downregulated in adipose tissue, and the ability of insulin to activate PDE3B and antagonize lipolysis is reduced (14-17). In one study, treatment of obese diabetic KKAy mice with pioglitazone, an insulin-sensitizing drug, increased PDE3B expression and its responsiveness to insulin and reduced serum FFA levels (14). 
A

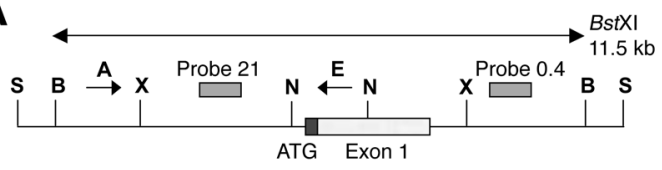

B

WT

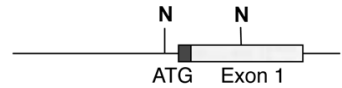

Initiation codon

Mutant
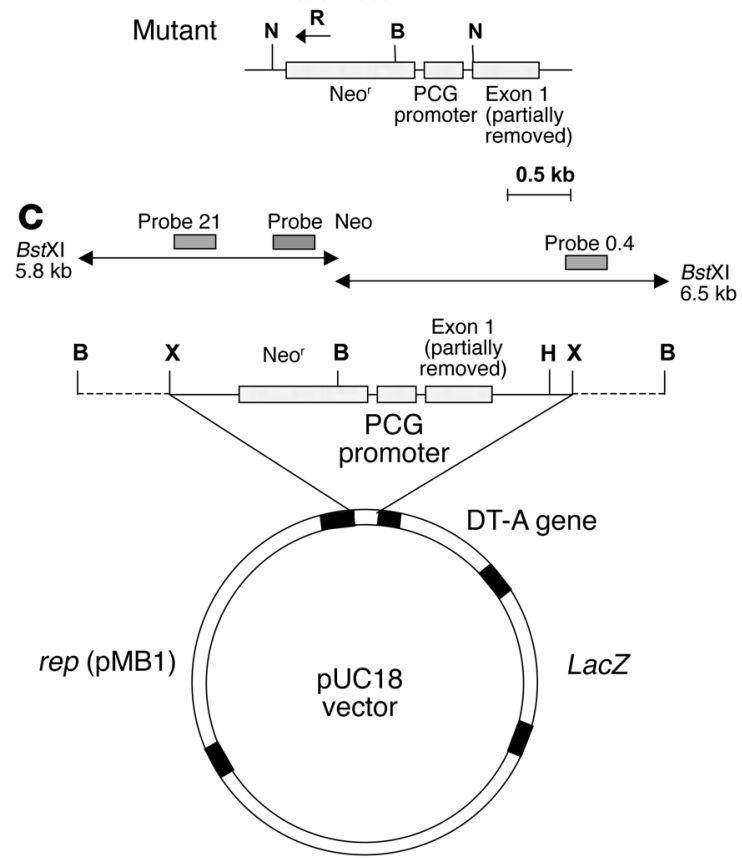

Bla $\left(A p^{R}\right)$

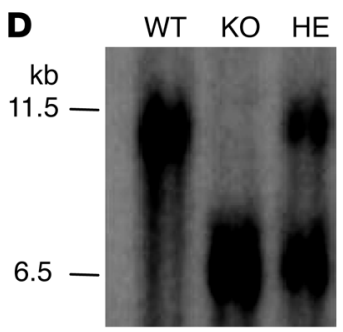

$\mathbf{E}$

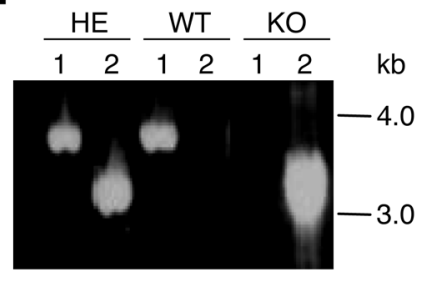

F
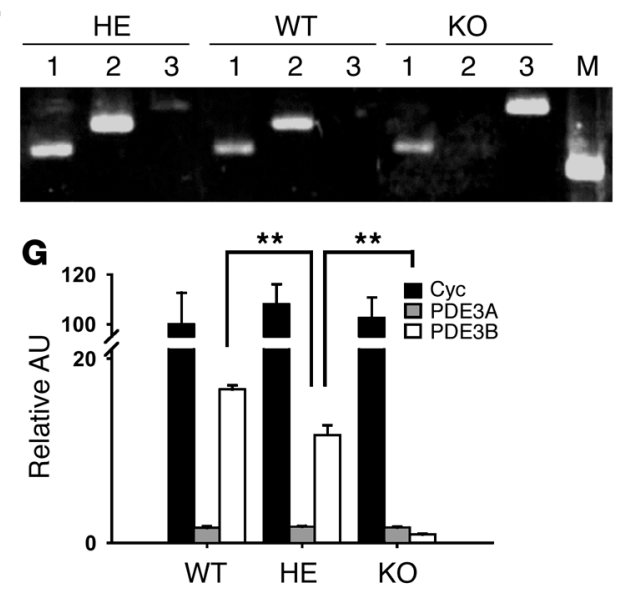

H

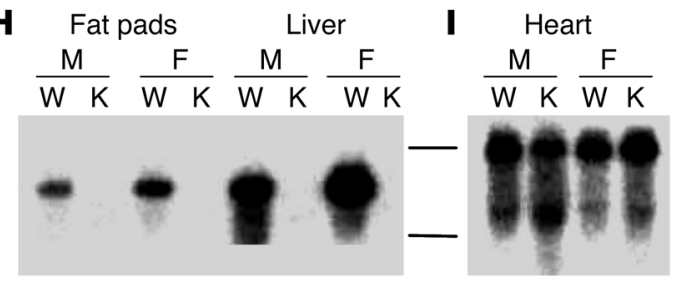

Figure 1

Targeted disruption of the murine Pde3b gene. (A) Structure of the approximately 13-kb Sal/PDE3B WT genomic fragment containing $5^{\prime}$-untranslated region and exon 1. (B) WT and disrupted KO gene fragments near exon 1. (C) Pde3b targeting vector. S, Sall; X, Xbal; B, BstXI; N, Notl; $\mathrm{H}$, HindIII. (D) Southern blot of WT, HE, and KO genomic DNA, digested with BstXI and hybridized to ${ }^{32} \mathrm{P}$-labeled probe 0.4 (see $\mathbf{A}$ and $\mathbf{C}$ ). (E) $P C R$ amplification of WT, HE, and KO genomic DNA using the specific primers $A, E$, and R indicated in $A$ and $B$ ( $A$ and $E$ for lane $1 ; A$ and $R$ for lane 2). (F) RT-PCR amplification of mRNA from WT, HE, and KO livers with primers described in Methods targeted for PDE3A (lane 1), PDE3B (lane 2), and $\mathrm{NeO}^{r}$ (lane 3). M, molecular weight marker. (G) Quantitation of cyclophilin A (Cyc), PDE3A, and PDE3B mRNAs in WT, HE, and KO mouse livers by real-time RT-PCR. Data were normalized to the quantity of WT cyclophilin A mRNA, taken as 100 AU. Values represent mean \pm SEM ( $n=4$ per genotype in triplicate assays). Data were similar in 2 other groups of WT and KO mice and 1 group of HE mice. ${ }^{* *} P<0.01$. (H and I) Northern blot of WT and KO mRNAs, using probe B for mPDE3B (fat pads and liver; $\mathbf{H}$ ) or probe A for mPDE3A (heart; I) as described in Methods. M, male; F, female; W, WT mRNA; K, KO mRNA.

To evaluate the physiological role(s) of PDE3B, we induced a targeted disruption in the murine $P d e 3 b$ gene by homologous recombination. $P d e 3 b-\mathrm{KO}$ mice exhibited multiple alterations in regulation of lipolysis, lipogenesis, and insulin secretion as well as signs of peripheral insulin resistance.

\section{Results}

Targeted disruption of $P d e 3 b$. Pde $3 b^{-/-}$mice were generated as described in Methods (Figure 1, A-C). Mice used for experiments reported here were progeny of at least 6-7 backcrosses of heterozygous (HE) F 1 mice with JAX 129/SvJ (pTyr ${ }^{c-c h} / \mathrm{pTyr}^{c}$ substrain) mice. Genotyping of the $\mathrm{F}_{2}$ generation mice by Southern blot analyses demonstrated the predicted $6.5-\mathrm{kb}$ restriction fragment in $\mathrm{KO}$ mice, and both $11.5-\mathrm{kb}$ (WT) and $6.5-\mathrm{kb}(\mathrm{KO})$ fragments in HE mice (Figure 1D). PCR carried out with A and R primers or A and E primers (Figure 1, A and B) amplified the expected approximately $3.0-\mathrm{kb}$ band with genomic DNA from the $\mathrm{KO}$ and HE mice or the approximately $3.3-\mathrm{kb}$ band from WT and HE mice, respectively (Figure 1E).

As shown in Figure 1F, using appropriately designed primers, PDE3A transcripts were amplified in mRNA from WT, HE, and $\mathrm{KO}$ mice; PDE3B transcripts were amplified in mRNA from WT and $\mathrm{HE}$, but not $\mathrm{KO}$ mice; and neomycin resistance gene-targeted (Neo ${ }^{r}$-targeted) mRNA was amplified in mRNA from $\mathrm{HE}$ and $\mathrm{KO}$ mice. As shown in Figure 1G, real-time quantitative 1-step RT-PCR using SYBR Green as the reporter fluorophore and primers from exons 2 and 3 indicated that PDE3B mRNA amplification in KO and $\mathrm{HE}$ livers was approximately $5 \%$ and $65 \%$, respectively, that of WT liver. In Northern blots, PDE3B probe B (from the portion of the Pde3b gene replaced by $\mathrm{NeO}^{r}$ ) detected approximately $5.5-\mathrm{kb}$ 

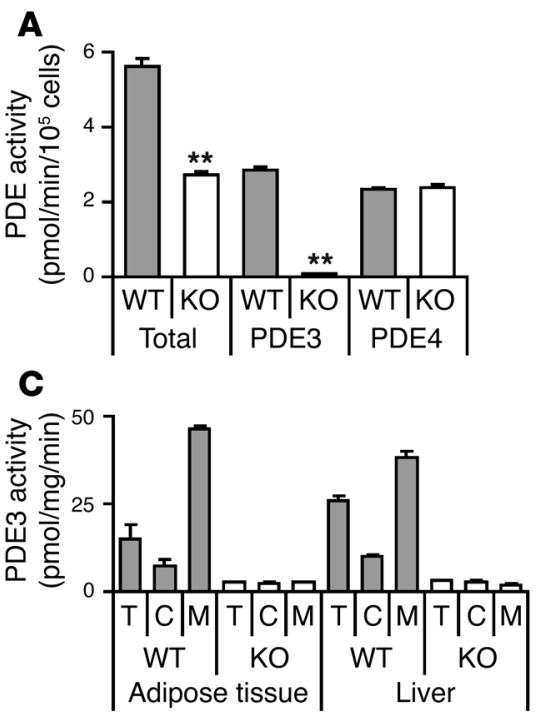
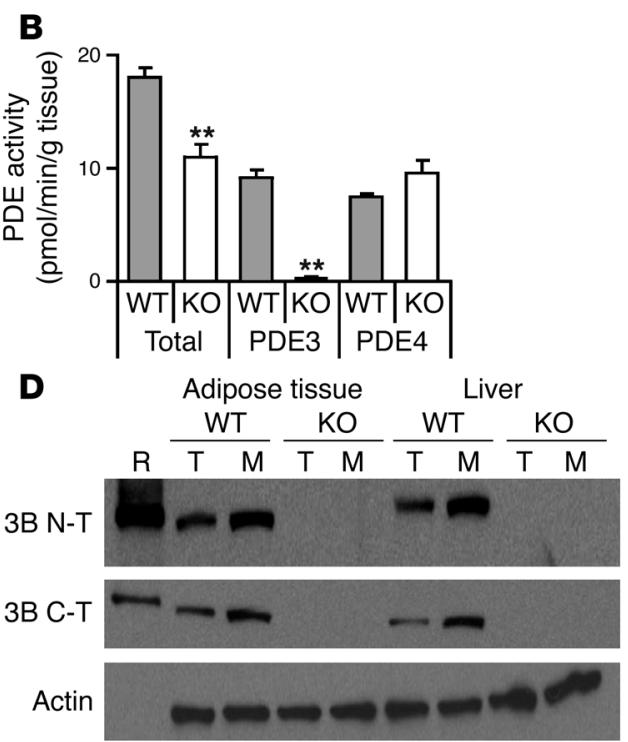

\section{Figure 2}

PDE activity and Western blots. (A and B) PDE activities in epididymal adipocytes prepared from 4-month-old WT and KO mice are presented as total, PDE3, and PDE4 activities. Values represent mean \pm SEM of duplicate assays ( $n=3$ mice per group), which were repeated with similar results. ${ }^{* *} P<0.01$. (C and D) PDE3 activities $(\mathbf{C})$ and protein expression (D) in adipose tissue and liver. Total cell lysate (T) as well as cytosol (C) and membrane fractions (M) were prepared from gonadal adipose tissue and livers from 4-month-old WT and KO mice $(n=10-11$ mice per group). (C) PDE3 activities (pmol cAMP hydrolyzed $/ \mathrm{min} / \mathrm{mg}$ protein) are expressed as mean \pm SEM (duplicate assays). (D) Western blots, each lane $30 \mu \mathrm{g}$ protein, except membrane fractions $(75 \mu \mathrm{g})$ for $\beta$-actin detection. Results are representative of 3 experiments. R, PDE3B recombinant protein. Immunoblotting was performed using a monoclonal anti- $\beta$-actin antibody and affinity-purified rabbit antibodies raised against $\mathrm{N}$-terminal (3B N-T; RKDERERDTPAMRSPPP, aa 2-18) or C-terminal (3B C-T; NASLPQADEIQVIEEADEEE, aa 1076-1095) sequences of PDE3B.

transcripts in mRNA from fat pads and liver of WT, but not KO, mice (Figure $1 \mathrm{H}$ ). In contrast, 2 heart mRNA transcripts (approximately 7.5 and $4.5 \mathrm{~kb}$ ) were detected using PDE3A probe A with mRNA from both the WT and KO mice (Figure 1I). Northern blots with Clontech MTN filters revealed PDE3 mRNAs of sizes similar to those shown in Figure 1, H and I (data not shown). As also shown in Figure 1G, the amount of PDE3A mRNA was much lower than that of PDE3B mRNA in WT livers and was not increased in $\mathrm{HE}$ or KO livers. Thus, results in Figure 1, G and I, indicate no evidence of compensatory changes in expression of PDE3A in $\mathrm{KO}$ mice (at least in liver and heart).

PDE3 activity in homogenates of isolated adipocytes was assessed by measurement of cAMP hydrolysis in the absence or presence of cilostamide, a specific PDE3 inhibitor (ref. 2; selective PDE3A and PDE3B inhibitors are not available). As shown in Figure 2A, PDE3 activity was virtually absent in KO adipocytes, indicating that PDE3B is the PDE3 isoform expressed in adipocytes. In isolated WT adipocytes, PDE3B accounted for almost one-half of the total PDE activity; and PDE4, somewhat less (Figure 2, A and B). PDE4 activity is that activity inhibited by $10 \mu \mathrm{M}$ rolipram, a selective PDE4 inhibitor (2). PDE4 activities were similar in WT and $\mathrm{KO}$ adipocytes, indicating that there was no compensatory increase in PDE4 in KO adipocytes. PDE3B accounted for most of the PDE3 activity in adipose tissue and liver (Figure 2C). Immunoreactive approximately $135-\mathrm{kd}$ PDE3B was not detected in homogenates $(\mathrm{T})$ or membrane fractions $(\mathrm{M})$ of adipose tissue and livers from $\mathrm{KO}$ mice (Figure 2D). As shown in Supplemental Figure 1 (supplemental material available online with this article; doi:10.1172/JCI24867DS1), residual PDE3 activity in livers from PDE3B KO mice could be account- ed for by PDE3A; lower molecular weight material not associated with PDE3 activity was detected with anti-PDE3B (C-T) in membrane fractions from WT and KO mice.

Characteristics of Pde $3 b-\mathrm{KO}$ mice. Newborn $\mathrm{KO}$ pups exhibited no obvious physical defects. Their growth and development, general behavior, and activity levels were similar to those of WT mice, and $\mathrm{KO}$ mice of both sexes were fertile. Most experiments were carried out with groups of age-matched WT and KO mice, whose dates of birth varied by $0-5$ days; the mice were usually older than 3-4 months. Pde3b-KO mice were slightly heavier than their WT counterparts (Supplemental Table 1) and exhibited variations in coat color from white to yellowish brown. When mice were fed normal chow (Figure $3 \mathrm{~A}$ ) or a $60 \%$-fat diet (data not shown), the weight of gonadal adipose tissue was lower in KO than WT mice (Figure 3A) and also represented a lesser percentage of body weight (data not shown). The mean cell diameter of $\mathrm{KO}$ adipocytes was significantly smaller than that of WT adipocytes, and the cell diameter distribution was shifted to a lower range (Figure 3, B and C). Weights of livers (Supplemental Table 1) as well as hearts and pancreata (data not shown) did not differ between WT and KO mice. TG content, however, was significantly increased in livers in $\mathrm{KO}$ mice and was associated with increased expression of fatty acid synthase (FAS) (Figure 3D).

Insulin-and catecholamine-mediated regulation of lipolysis is altered in Pde3b-KO mice. To assess the impact of the absence of adipocyte $\mathrm{PDE} 3 \mathrm{~B}$ on catecholamine-induced lipolysis in vivo, $\mathrm{CL}$ 316,243 (CL; a specific $\beta_{3}$ receptor agonist $-\beta_{3}$ receptors are the predominant subtype in rodent adipocytes; ref. 18) and isoproterenol (ISO; a general $\beta$ receptor agonist) were administered by i.p. injection, and their effects on serum glycerol and 

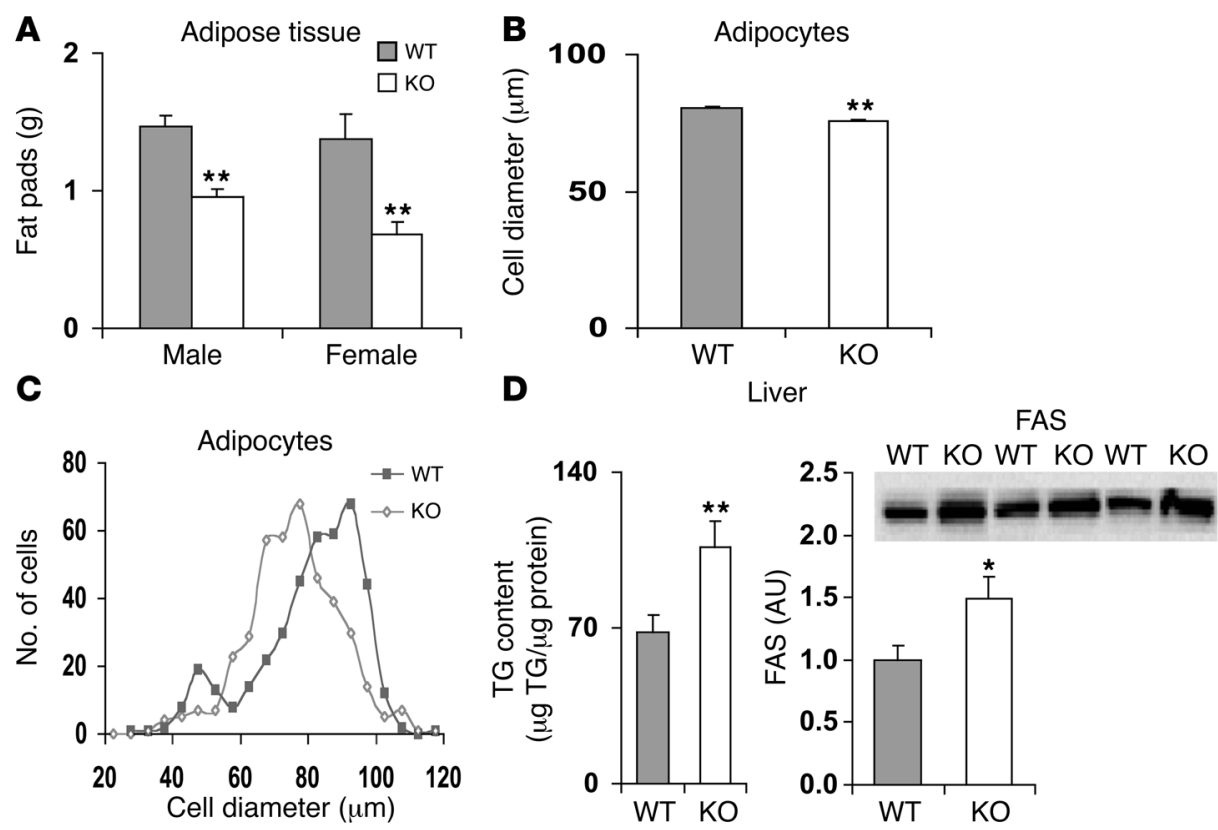

Figure 3

Gonadal fat weight, adipocyte diameters, and liver TG and FAS content in WT and Pde3b-KO mice. (A) WT and KO mice, housed 2 per cage and with free access to food and water, were fed normal chow. Caloric contents were $10 \%, 20 \%$, and $70 \%$ fat, protein, and carbohydrate, respectively. For weight measurements, gonadal fat pads were collected from 6-month-old WT and KO mice $(n=6-8$ mice per group). Data (mean \pm SEM) were similar in 2 other experiments. (B and C) Diameter of epididymal adipocytes from age-matched 5-month-old WT and KO mice. (B) Cell diameter. Values are mean \pm SEM ( $n=357$ WT and $447 \mathrm{KO}$ cells). (C) Diameter distribution. The numbers of adipocytes with 5- $\mu \mathrm{m}$ intervals in their diameters were counted and plotted. Results are representative of 4 experiments. (D) Liver TG and FAS content. Liver TG content of 3to 3.5-month-old male WT and KO mice was measured as described in Methods. Values are mean \pm SEM ( $n=18$ per group). FAS content was determined by Western blot of liver homogenates (45 $\mu$ g protein/lane) from WT and KO mice. Immunodetection was performed with anti-FAS antibody, and FAS bands were quantified. Values are mean \pm SEM $\left(n=3\right.$ per group). ${ }^{*} P<0.05 ;{ }^{\star *} P<0.01$.

FFA levels were measured. Basal levels of glycerol and FFA were similar in fed WT and $\mathrm{KO}$ mice. As shown in Figure 4, CL and ISO increased lipolysis, i.e., serum glycerol (Figure 4A) and FFA (Figure 4B) levels, to a greater extent in $\mathrm{KO}$ than in WT mice. In isolated adipocytes (Figure 4C), CL, which at low concentrations was more effective than ISO, also stimulated lipolysis to a greater extent in adipocytes isolated from KO mice than from WT mice. Consistent with current ideas that activation of PDE3B and reduction of CAMP are critical in the antilipolytic action of insulin (7), insulin inhibited catecholamine-activated lipolysis in WT, but not KO, adipocytes (Figure 4D). After fasting for 20 hours, serum glycerol (Figure 5A) and FFA (Figure 5B) levels were increased in $\mathrm{KO}$ mice. As shown in Figure 5C, CL stimulated lipolysis to a greater extent in adipocytes from fed $\mathrm{KO}$ mice than fed WT mice. CL-stimulated lipolysis was further enhanced in adipocytes from fasted WT, but not $\mathrm{KO}$, mice, perhaps due to the fact that lipolytic pathways were activated to a greater extent in fasted KO than WT mice (Figure 5, A and B). Insulin inhibited CL-stimulated lipolysis in adipocytes from fed and fasted WT, but not KO, mice (Figure 5C).

Insulin secretion is increased in Pde $3 b-K O$ mice. To more directly assess the effects of the absence of PDE3B in pancreatic $\beta$ cells, we examined glucose-stimulated insulin secretion by pancreatic islets isolated from WT and $\mathrm{KO}$ mice. As shown in Figure 6A, and in agreement with previous results by us and others $(5,12,13,19,20)$, in the presence of $16.7 \mathrm{mM}$ glucose, without or with GLP-1, glucose-stimulated insulin secretion was increased to a greater extent in $\mathrm{KO}$ than in WT islets, indicative of increased content of, and/or increased responsiveness to, cAMP in Pde $3 b$-deficient islets. Immunohistochemical analyses of pancreata from WT and $\mathrm{KO}$ mice showed no significant differences in islet size and expression/localization of insulin, glucagon, the $\beta$ cell-specific transcription factor PDX-1, glucose transporter-2 (GLUT-2), and $\beta$ cell glucokinase (data not shown).

In intact mice, administration of $\beta_{3}$ receptor agonists are known to induce insulin secretion $(21,22)$. Administration of i.p. CL increased serum insulin levels to a greater extent in $\mathrm{KO}$ than in WT mice in a time- (Figure 6B) and concentration-dependent (data not shown) manner. Maximal increases were observed within 20 minutes after injection. Administration of ISO also increased serum insulin levels to a greater extent in $\mathrm{KO}$ mice (Figure 6C), but ISO was less effective than CL. Because stimulatory effects of $\beta_{3}$ receptor agonists on insulin secretion are thought to be indirect and related to the presence of white adipose tissue depots (21, 22 ), the effects of CL are presumably related to production and/or release of an adipocytokine(s) or incretin(s). Taken together with the results shown in Figure 6A, these observations suggest that in $\mathrm{Pde} 3 \mathrm{~b}$-KO mice, there is increased secretion of, and/or enhanced islet-responsiveness to, these agents.

$P d e 3 b-K O$ mice are insulin resistant. As shown in Supplemental Table 1, blood glucose and serum concentrations of glycerol, TGs, insulin, and FFAs were not significantly different in fed WT and KO mice. Although serum glycerol and FFA levels were increased in fasted $\mathrm{KO}$ mice (Figure 5), blood glucose and serum 

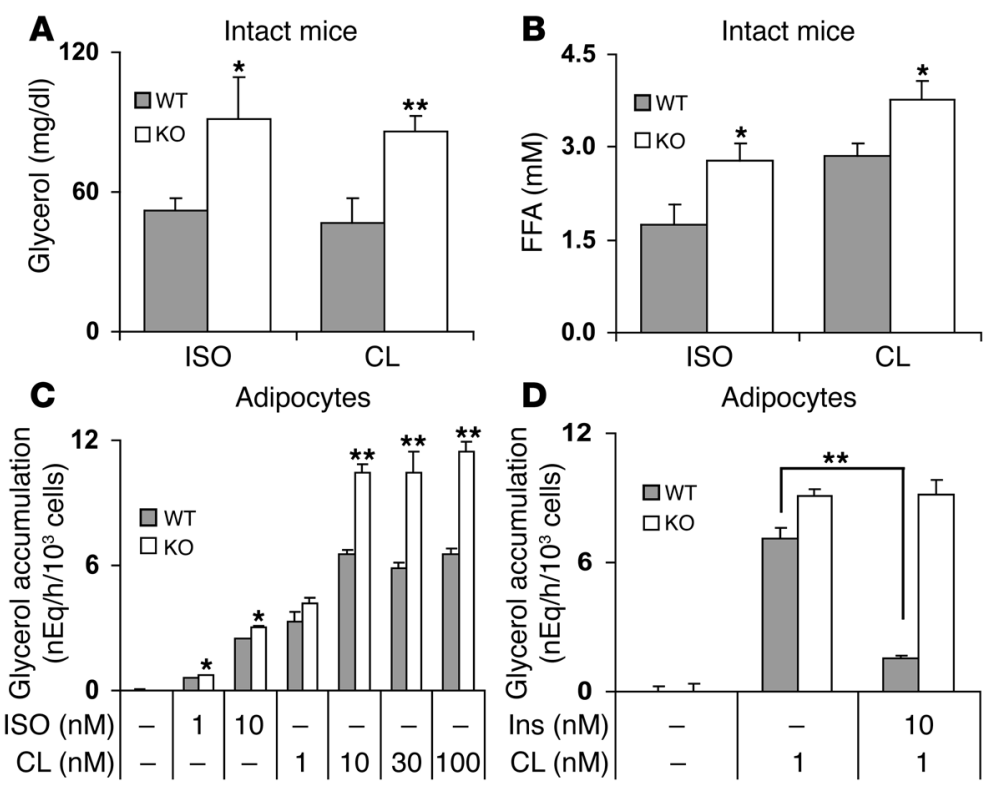

Adipocytes

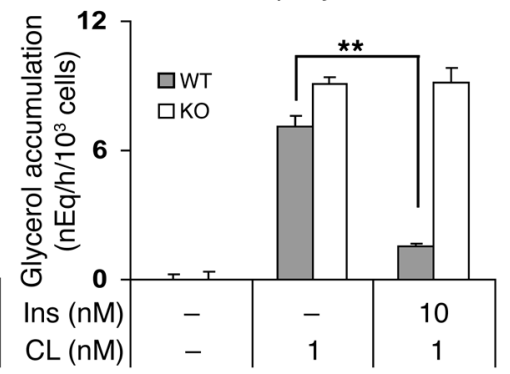

\section{Figure 4}

Effects of ISO, CL, and insulin on lipolysis in intact mice and adipocytes. (A and B) ISO or CL (1.0 mg/ $/ \mathrm{kg}$ each) in PBS, or PBS alone, was injected i.p. (10 ml/kg) into 6-month-old WT and KO mice. After 20 minutes, serum glycerol (A) and FFA (B) levels were quantified. Values are mean \pm SEM ( $n=4$ per group). Differences between serum glycerol or FFA concentrations after PBS alone (basal) and after drug administration are shown. Basal values in WT and KO mice were $20.5 \pm 2.7$ and $23.7 \pm 1.2 \mathrm{mg} / \mathrm{dl}$ glycerol, respectively, and $1.49 \pm 0.21$ and $1.13 \pm 0.25 \mathrm{mM}$ FFA, respectively. Data were similar in 3 other experiments. (C and D) Adipocytes $(0.4 \mathrm{ml}, 5 \%$ [vol/vol]) prepared from epididymal fad pads of 6-month-old WT and KO mice were incubated for 60 minutes at $37^{\circ} \mathrm{C}$ in Krebs-Ringer-HEPES buffer alone or with the indicated concentrations of ISO, CL, or insulin (Ins). Lipolysis was measured as glycerol accumulation in the medium. Data are mean \pm SEM of 3 incubations (duplicate assays). (C) Basal glycerol values were $0.13 \pm 0.02$ and $0.12 \pm 0.01 \mathrm{nEq} / \mathrm{h} / 10^{3}$ cells for WT and KO, respectively. Data were similar in 3 other experiments. (D) Basal glycerol values were $0.24 \pm 0.13$ and $0.13 \pm 0.08 \mathrm{nEq} / \mathrm{h} / 10^{3}$ cells for WT and KO, respectively. Data were similar in 2 other experiments. ${ }^{*} P<0.05 ;{ }^{\star \star} P<0.01$. insulin levels were not changed (data not shown). Results of a number of experiments, however, indicated that $\mathrm{KO}$ mice were insulin resistant. Thus, despite the very high serum insulin concentrations in $\mathrm{KO}$ mice within 20 minutes after i.p. administration of CL, reduction in, or disposal of, blood glucose was not greater in CL-treated $\mathrm{KO}$ mice (Figure 6, $\mathrm{C}$ and D). As also shown in Figure 6C, within 10-20 minutes after i.v. injection of CL, serum insulin levels were also increased to a significantly greater extent in KO than in WT mice, although the differences between WT and KO mice were smaller following i.v. injection than i.p. injection. Despite the approximately 40 -fold increase in serum insulin levels in the $\mathrm{KO}$ mice following i.v. administration of CL, there was much less removal or disposal of glucose in CL-treated
KO mice than in CL-treated WT mice (Figure 6D). In addition, during insulin tolerance tests (ITTs) following i.p. injection of insulin to male mice, insulin was much less effective in reducing blood glucose and serum FFA levels in male KO than WT mice (Figure 7, A and B). Although effects of insulin on glucose disposal were similar in female WT and KO mice, insulin was less effective in reducing FFA levels in KO females than in WT females (data not shown). These results are consistent with the lack of the antilipolytic action of insulin in isolated adipocytes from KO mice (Figures 4 and 5). Furthermore, although clearance of blood glucose was similar in WT and KO mice during glucose tolerance tests (GTTs) following administration of i.p. glucose loads (Figure 7C), serum insulin levels were higher in older

\section{Figure 5}

Effects of fasting on lipolysis in intact mice and adipocytes. (A and B) WT and KO mice (4 months old) were fed ad libitum (NF) or fasted for 20 hours (F). Serum glycerol (A) and FFA (B) levels, determined as described in Methods, are presented as mean $\pm \operatorname{SEM}(n=6-7$ mice per group). Results were similar to those from another group of fed and fasted WT and KO mice. (C) WT and KO mice (5 months old) were fasted for 20 hours before preparation of adipocytes, which were incubated for 60 minutes at $37^{\circ} \mathrm{C}$ with the indicated concentrations of $\mathrm{CL}$ and insulin. Increases from basal glycerol values are shown. Basal values were $0.16 \pm 0.01$ and $0.12 \pm 0.00 \mathrm{nEq} / \mathrm{h} / 10^{3}$ cells for WT fed and fasted adipocytes, respectively, and $0.09 \pm 0.01$ and $0.09 \pm 0.01 \mathrm{nEq} / \mathrm{h} / 10^{3}$ cells for $\mathrm{KO}$ fed and fasted adipocytes, respectively. Data are mean \pm SEM of 3 incubations (duplicate assays). ${ }^{\star} P<0.05 ;{ }^{* *} P<0.01$.
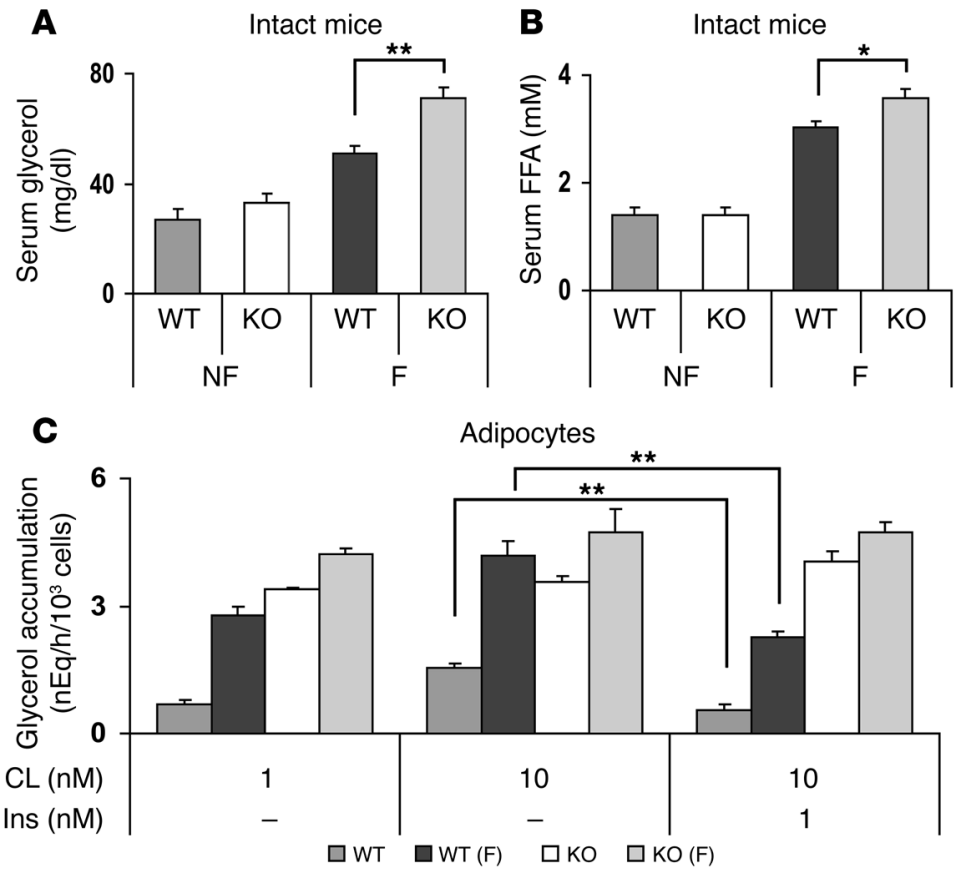


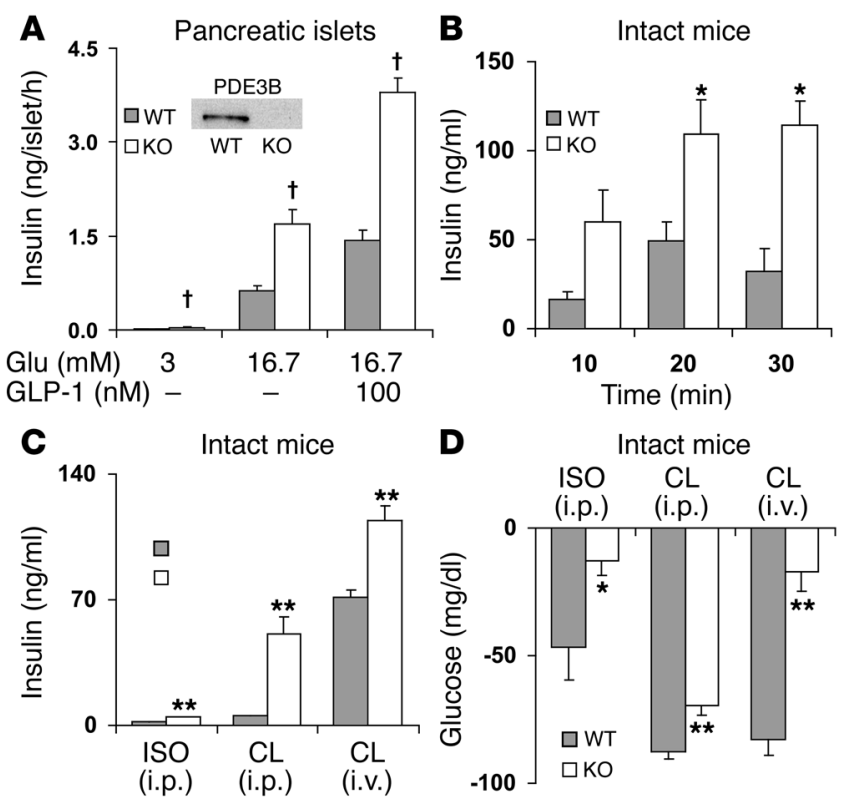

(9-month-old) KO males (Figure 7D) and females (data not shown); the increase in insulin secretion was not observed during GTTs in younger mice. The increase in serum insulin levels during GTTs observed in older $\mathrm{KO}$ mice is indicative of an altered exocytotic or secretory response to a glucose load of pancreatic $\beta$ cells that lack PDE3B, and is consistent with the increased responsiveness of isolated KO islets to glucose and GLP-1 (Figure 6A).

To gain insight into the possible tissue loci of the insulin resistance observed in the different settings, i.e., i.p. ITTs, i.p. GTTs, and i.p. administration of $C L$, hyperinsulinemic-euglycemic clamps were performed. As shown in Table 1, after 16 hours of fasting, basal glucose, insulin, and endogenous glucose production (EGP) were not significantly different in WT and KO mice, and clamp blood glucose levels also were not significantly different between WT and KO mice (122 \pm 3 and $119 \pm 1 \mathrm{mg} / \mathrm{dl})$. Under the hyperinsulinemic clamp conditions, KO mice exhibited slightly lower whole-body glucose uptake and reduced uptake in brown adipose tissue than in WT mice $(P<0.09)$, but these differences were not statistically significant. The steadystate glucose infusion rate required to maintain euglycemia was significantly higher in WT $(159 \pm 13 \mu \mathrm{mol} / \mathrm{min} / \mathrm{kg})$ than in $\mathrm{KO}$ mice $(86 \pm 7 \mu \mathrm{mol} / \mathrm{min} / \mathrm{kg} ; P<0.01)$, suggesting impaired insulin responsiveness in $\mathrm{KO}$ mice. Insulin-induced suppression of

\section{Figure 7}

ITTs and GTTs. (A and B) Male 5-month-old WT and KO mice were fasted overnight for 20 hours prior to i.p. injection $(10 \mathrm{ml} / \mathrm{kg})$ of insulin $(0.5 \mathrm{U} / \mathrm{kg})$ in PBS or PBS alone, and blood glucose (A) and serum FFA (B) levels were measured at the indicated times. Glucose concentrations $(\mathbf{A})$ are reported relative to those at time 0 . Basal glucose values in WT and KO mice were $70 \pm 3$ and $66 \pm 3 \mathrm{mg} / \mathrm{dl}$, respectively. Data (mean \pm SEM; $n=6$ mice per group) were similar in 8 (A) and 2 (B) other experiments. (C and $\mathbf{D}$ ) Male 9-month-old WT and KO mice were fasted overnight, with free access to water. At the indicated times after i.p. injections $(10 \mathrm{ml} / \mathrm{kg})$ of PBS alone or of glucose $(2 \mathrm{~g} / \mathrm{kg})$ in PBS, blood glucose (C) and serum insulin (D) levels were quantified. Data (mean $\pm \mathrm{SEM} ; n=6$ mice per group) were similar in 2 other experiments. ${ }^{\star} P<0.05 ;{ }^{* \star} P<0.01$.

\section{Figure 6}

Differences in insulin secretion from pancreatic islets, serum insulin concentrations, and blood glucose disposal in WT and $P d e 3 b-K O$ mice. (A) Insulin accumulation during incubation of isolated pancreatic islets for 1 hour with 3 or $16.7 \mathrm{mM}$ glucose and without or with $100 \mathrm{nM} \mathrm{GLP}-1$ as indicated. Data are mean $\pm \operatorname{SEM}(n=4)$. Inset: Immunoreactive PDE3B was detected by Western blots of WT, not KO, homogenates. (B) $\mathrm{CL}(1.0 \mathrm{mg} / \mathrm{kg})$ in PBS or PBS alone was injected i.p. $(10 \mathrm{ml} / \mathrm{kg})$ into 6-month-old WT and KO mice. At the indicated times, differences from time 0 (basal) in serum insulin levels were quantified. Basal insulin levels in WT and KO mice were $1.4 \pm 0.2$ and $2.6 \pm 0.1 \mathrm{ng} / \mathrm{ml}$, respectively. Data (mean \pm SEM; $n=4$ mice per group) are representative of 3 experiments. ( $\mathbf{C}$ and $\mathbf{D})$ ISO or $\mathrm{CL}(1.0 \mathrm{mg} / \mathrm{kg})$ in PBS or PBS alone were injected i.p. or i.v. $(10 \mathrm{ml} / \mathrm{kg})$ into 3- (i.p) or 4-month-old (i.v.) WT and $\mathrm{KO}$ mice. After 20 minutes, tail blood was collected, and changes from basal serum insulin (C) and blood glucose (D) levels were measured. Basal values were similar in PBS-treated WT and KO mice. Data (mean \pm SEM; $n=4-5$ mice per group) are representative of 3 experiments. ${ }^{*} P<0.05$; ${ }^{\star \star} P<0.01 ;{ }^{\dagger} P<0.001$.

EGP was markedly lower in $\mathrm{KO}$ mice $(30.9 \% \pm 8.6 \%$ in $\mathrm{KO}$ versus $88.7 \% \pm 6.7 \%$ in WT mice; $P<0.01$ ), suggesting that insulin does not effectively inhibit hepatic glucose output in KO mice. Thus, in regard to dysregulation of glucose homeostasis in KO mice, the liver appears to play a critical role.

Insulin and cAMP signaling, PPAR $\gamma$ coactivator-1 $\alpha /$ phosphoenolpyruvate carboxykinase expression, inflammation markers, and lipid metabolism are altered in livers and adipocytes from $\mathrm{KO}$ mice. Although it is not possible to precisely determine the role of the liver in the development of insulin resistance in the $\mathrm{KO}$ mice, a number of changes that may contribute were identified. As shown in Figure 3D, TG content and FAS expression were significantly increased in livers from Pde3b-KO mice. As shown in Figure 8A, cAMP content was increased in liver extracts from $\mathrm{KO}$ mice, consistent with increased phosphorylation of PKA substrates (Figure 8B) and cAMP regulatory element-binding protein (CREB) (Figure 8C). Furthermore, the content of PPAR $\gamma$ coactivator- $1 \alpha$ (PGC- $1 \alpha$ ), a transcriptional factor regulated by CREB, and phosphoenolpyruvate carboxykinase (PEPCK), a key gluconeogenic enzyme, was increased in KO livers, the latter especially in fasted animals (Figure 8C). Expression of PGC-1 $\alpha$, PEPCK, and glucose-6-
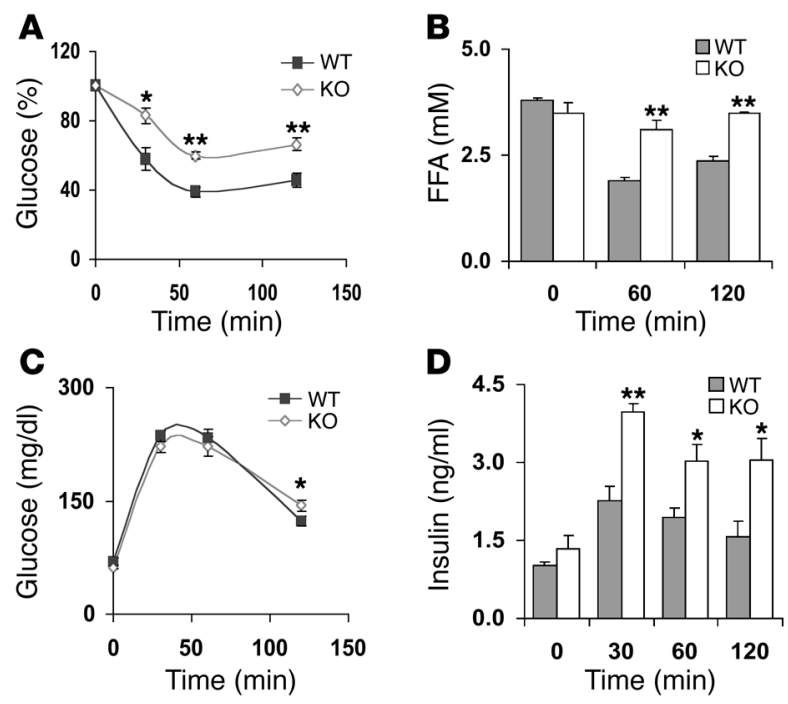
Table 1

Hyperinsulinemic-euglycemic clamps

$\begin{array}{lccc} & \text { WT } & \text { KO } & \text { P value } \\ \text { Clamp glucose }(\mathrm{mg} / \mathrm{dl}) & 122 \pm 3 & 119 \pm 1 & \\ \text { Glucose infusion rate }(\mu \mathrm{mol} / \mathrm{kg} / \mathrm{min}) & 159 \pm 13 & 86 \pm 7 & <0.01 \\ \text { EGP ( } \mu \mathrm{mol} / \mathrm{kg} / \mathrm{min}) & & & \\ \quad \text { Basal } & 66 \pm 3 & 75 \pm 4 & \\ \quad \text { Clamp } & 7 \pm 5 & 52 \pm 7 & <0.01 \\ \text { Basal EGP suppression (\%) } & 88.7 \pm 6.7 & 30.9 \pm 8.6 & <0.01 \\ \text { Glucose uptake ( } \mu \mathrm{mol} / \mathrm{kg} / \mathrm{min}) & & & \\ \quad \text { Whole body } & 166 \pm 12 & 138 \pm 8 & \\ \quad \text { Muscle } & 247 \pm 21 & 197 \pm 23 & \\ \quad \text { BAT } & 1599 \pm 324 & 818 \pm 115 & \\ \text { WAT } & 63 \pm 17 & 73 \pm 17 & \\ & & & \end{array}$

Clamps were performed using 5-month-old WT $(n=6)$ and KO $(n=6)$ mice. After fasting overnight and basal sampling (time 0 ), insulin was administered via continuous infusion for the duration of the 2 hours clamps. Blood glucose $(20 \%)$ was infused at variable rates to maintain plasma glucose at basal concentrations. BAT, brown adipose tissue; WAT, white adipose tissue.

phosphatase mRNAs were also significantly increased in fasted KO compared with fasted WT livers (Table 2), consistent with enhanced glucose production in KO livers. In addition, expression of tribbles 3 (TRB3) protein (Figure 8C) and mRNA (Table 2) was increased in fasted KO livers. Gene expression of TRB3, an inhibitor of PKB activation, is regulated by PGC- $1 \alpha$ and PPAR $\alpha$, and induction of TRB 3 is thought to be important in development of hepatic insulin resistance by PGC-1 $\alpha$ (23). As shown in Figure 9A, in extracts from KO livers, tyrosine phosphorylation of insulin receptor substrate-1 (IRS-1) was decreased without any change in total IRS-1. Serine phosphorylation of PKB and forkhead (Drosophila) homolog (rhabdomyosarcoma) like 1 (FKHRL1) was decreased, and tyrosine phosphorylation of glycogen synthase kinase-3 (GSK-3) was increased in KO liver extracts, consistent with decreased signaling via PKB, a critical kinase involved in insulin-mediated effects on glucose and lipid metabolism (24). With respect to stress/inflammation signals (Figure 9B), in livers from KO mice, phosphorylated JNK (but not total JNK), which could be important in increased serine phosphorylation of IRS-1, was increased. As analyzed by realtime RT-PCR, levels of SOCS-3 mRNA and mRNAs of proinflammatory cytokines IL-1, IL-6, TNF- $\alpha$, and plasminogen activator inhibitor-1 (PAI-1) were increased in fasted KO liver (Table 2). Many of these changes could contribute to development of insulin resistance in $\mathrm{KO}$ mice (25).

Consistent with hyperinsulinemic-euglycemic clamps in intact mice, no significant differences in insulin-induced glucose uptake were detected in isolated adipocytes from WT and KO mice (Figure 10A). Although basal lipogenesis was reduced in adipocytes from $\mathrm{KO}$ mice, insulin-stimulated lipogenesis was significantly enhanced in $\mathrm{KO}$ adipocytes (Figure 10B), which was explained in part by an increase in the expression of FAS (Figure 10C). As shown in Figure 10D, insulin-induced phosphorylation and activation of PKB were similar in WT and KO adipocytes.

Serum adiponectin, but not leptin, is increased in $\mathrm{KO}$ mice. In addition to its traditional role as a storage depot for fat, adipose tissue is an important secretory organ of multiple factors, includ- ing so-called adipokines, which affect inflammation, appetite, insulin sensitivity, metabolism, and energy expenditure (26-28). One such adipokine, adiponectin, enhances insulin sensitivity in peripheral tissues, especially liver $(27,29,30)$. In mice on normal chow (Figure 11A) or before or after (Figure 11B) 14 weeks on a $60 \%$-fat diet, serum adiponectin concentrations were higher in KO mice (male and female) than in WT mice and did not change significantly after an overnight fast (Figure 11A). Adiponectin mRNA expression was increased in adipose tissue from Pde3b-KO mice fed normal chow (Figure 11C). There were no significant differences in serum leptin between WT and KO mice fed normal chow (Supplemental Table 1). Administration of CL decreased serum leptin (data not shown) and adiponectin (Figure 11D) in both WT and KO mice, indicating appropriate responses to acute increases in cAMP.

\section{Discussion}

The phenotypic characteristics of Pde3b-KO mice indicate that PDE3B plays an unique role in adipocytes, liver, and pancreatic $\beta$ cells and is not apparently functionally compensated for by other PDE gene families or by the other PDE3 family member, PDE3A.

Results of hyperinsulinemic-euglycemic clamp studies suggested that with respect to dysregulation of glucose metabolism, the liver is a critical site in the development of systemic insulin resistance in $\mathrm{KO}$ mice, where a number of defects were detected. The expression level and phosphorylation states of a number of insulin- and cAMP- signal transduction components were altered in KO livers (Figures 8 and 9), which were consistent with development of insulin resistance and/or increased glucose production. In addition, expression of TRB3, an inhibitor of PKB activation thought to be important in induction of hepatic insulin resistance by PGC-1 $\alpha$ (23), was increased in fasted KO livers, as was expression of PEPCK and glucose-6-phosphatase, key

\section{Table 2}

Real-time RT-PCR quantification of selected mRNAs in livers of fasted and fed WT and KO mice

\begin{tabular}{lcllc}
\hline Gene & WT, NF & K0, NF & WT, FA & K0, F \\
Pgc1a & 1.0 & $1.3 \pm 0.3$ & $2.5 \pm 0.4$ & $5.6 \pm 1.2^{\mathrm{B}}$ \\
G6Pase & 1.0 & $1.8 \pm 0.3$ & $2.1 \pm 0.3$ & $4.0 \pm 0.6^{\mathrm{B}}$ \\
Pepck & 1.0 & $1.1 \pm 0.2$ & $1.8 \pm 0.3$ & $3.6 \pm 0.7^{\mathrm{B}}$ \\
Trb3 & 1.0 & $1.2 \pm 0.2$ & $1.7 \pm 0.1$ & $2.4 \pm 0.2^{\mathrm{B}}$ \\
II1 & 1.0 & $1.3 \pm 0.3$ & $2.4 \pm 0.1$ & $4.7 \pm 0.5^{\mathrm{B}}$ \\
II6 & 1.0 & $1.1 \pm 0.2$ & $2.4 \pm 0.3$ & $3.7 \pm 0.3^{\mathrm{B}}$ \\
Tnfa & 1.0 & $3.2 \pm 0.5^{\mathrm{C}}$ & $2.5 \pm 0.2$ & $5.4 \pm 0.4^{\mathrm{C}}$ \\
Socs3 & 1.0 & $2.9 \pm 0.6^{\mathrm{B}}$ & $3.2 \pm 0.6$ & $7.3 \pm 1.3^{\mathrm{B}}$ \\
Pai1 & 1.0 & $0.9 \pm 0.1$ & $2.7 \pm 0.3$ & $5.7 \pm 1.1^{\mathrm{B}}$
\end{tabular}

Total RNA was prepared from approximately $0.1 \mathrm{~g}$ frozen liver from 5 month-old WT and KO male mice ( $n=4$ per group) either nonfasted (NF) or fasted for 6 hours (F) using Tripure reagent (Roche Diagnostics). mRNAs for the indicated genes were quantified by real-time RT-PCR (all assays in duplicate), with primers described in Methods. Cyclophilin A gene expression was used as an internal control for normalization of amounts of mRNA in different mice. Data are expressed as arbitrary units, mean \pm SEM ( $n=4$ mice per group, all assays in duplicate), with mRNA expression of genes in WT, nonfasted group taken as 1.0. AExpression of these genes (but not cyclophilin $A$ or $P d e 3 b$ ) was significantly increased $(P<0.05)$ in fasted WT versus nonfasted WT mice. ${ }^{\mathrm{B} P}<0.05$ versus WT. ${ }^{\mathrm{C}} P<0.01$ versus WT. The experiment was repeated with similar results, with RNA prepared from a second set of fasted and nonfasted WT and KO mice. G6Pase, glucose-6-phosphatase. 


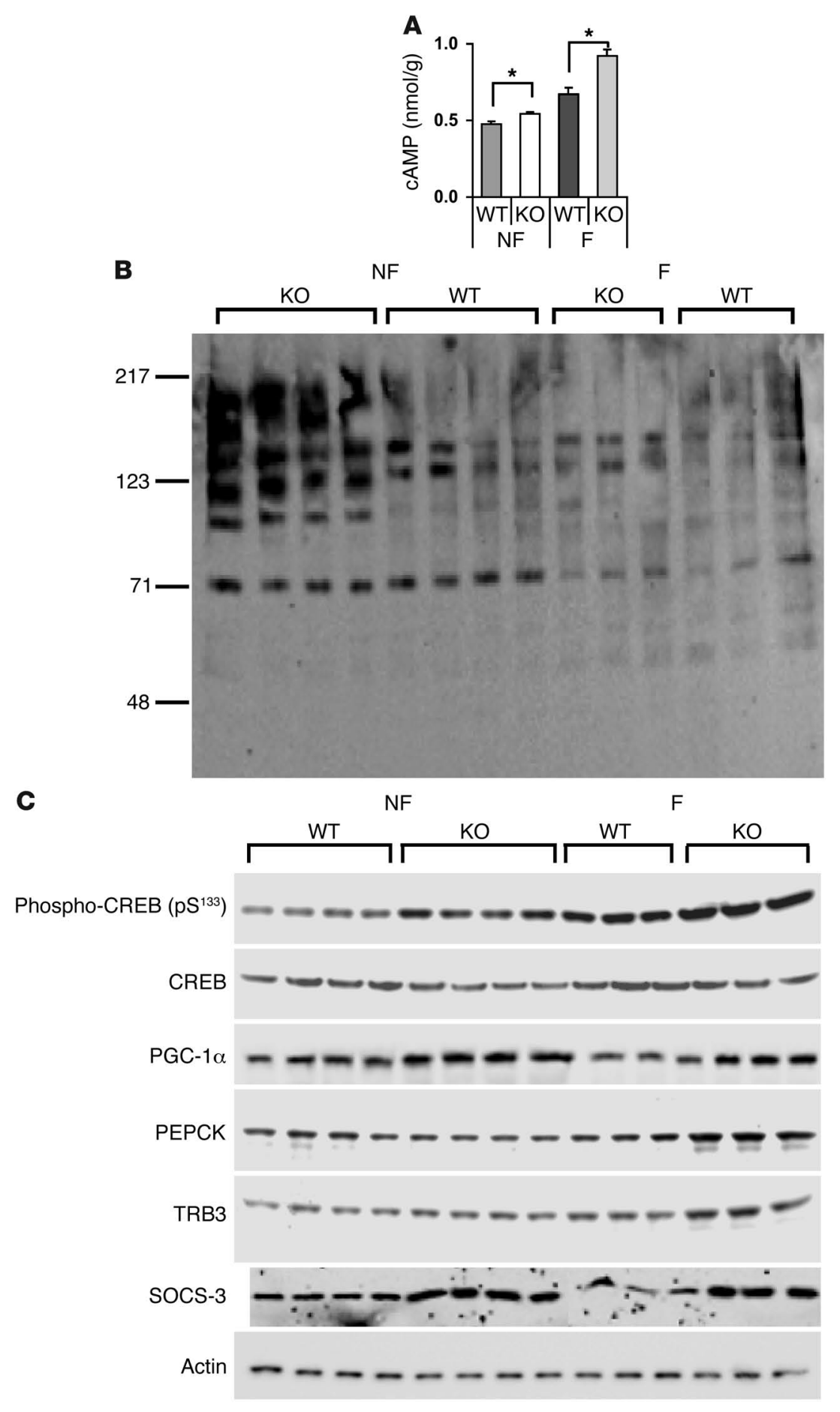

\section{Figure 8}

Hepatic cAMP content and gluconeogenic gene expression in nonfasted and 6-hour-fasted WT and Pde $3 b-K O$ mice. (A) Hepatic cAMP content. cAMP was measured in liver extracts from 5-month-old WT and Pde3b-KO mice either fed or fasted for 6 hours as described in Methods. Values on the $y$ axis represent nanomoles of cAMP per gram of liver. Data (mean \pm SEM; $n=4$ per group), which represent duplicate assays, were similar in a second group of fasted and nonfasted WT and KO mice. (B and C) Western blotting of liver lysates (50 $\mu \mathrm{g}$ protein/lane) was performed as described in Methods. $n=4 \mathrm{fed}$, 3 fasted mice per group. Data from a second, identical group of fed $(n=4)$ and 6-hour fasted $(n=3)$ WT and KO mice were similar. (B) Immunodetection with anti-PKA substrates antibody, which detects substrate proteins phosphorylated by cAMP-dependent protein kinase. (C) Immunodetection with anti-phospho-CREB ( $\left.\mathrm{pS}^{133}\right)$; antiCREB; anti-PGC-1 $\alpha$; anti-PEPCK; anti-TRB3; anti-SOCS-3; and anti-actin antibodies. gluconeogenic enzymes. With respect to stress/inflammation signals, in livers from KO mice, phosphorylated JNK (which may be important in increased serine/decreased tyrosine phosphorylation of IRS-1), but not total JNK, was increased. As assessed by realtime RT-PCR, increased levels of mRNAs of SOCS-3 and several proinflammatory cytokines, IL-1, IL-6, TNF- $\alpha$, and PAI-1, were detected in fasted KO livers. Liver TG and FAS contents were significantly increased in KO livers; this could be important in development of systemic insulin resistance. Ample evidence in humans and rodents points to an inverse relationship between hepatic TG content and insulin's effectiveness in regulating hepatic glucose metabolism. Excessive accumulation of TGs within the liver is recognized as part of the metabolic syndrome (31-33). In addition, the lack of PDE3B in hepatocytes could influence glycogen metabolism, since activation of PDE3B by insulin may be involved in its antiglycogenolytic effects (11).

Increased levels of FFA have been implicated in $\beta$ cell dysfunction and increased peripheral insulin resistance (34). Consistent 

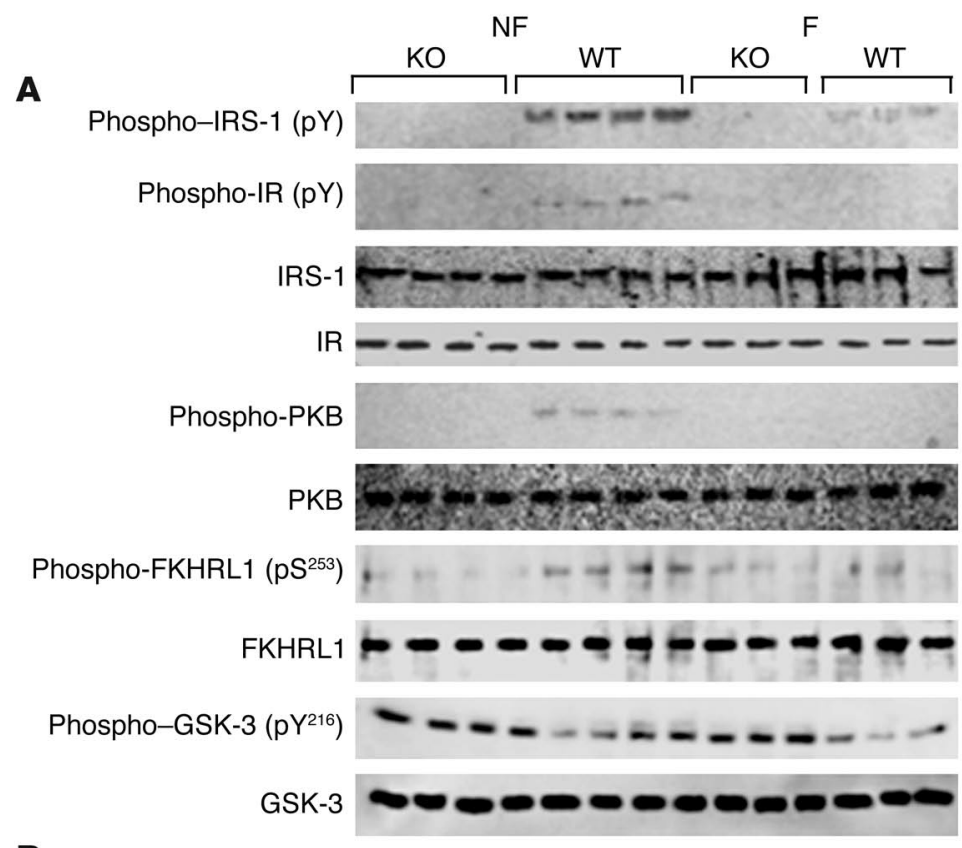

B

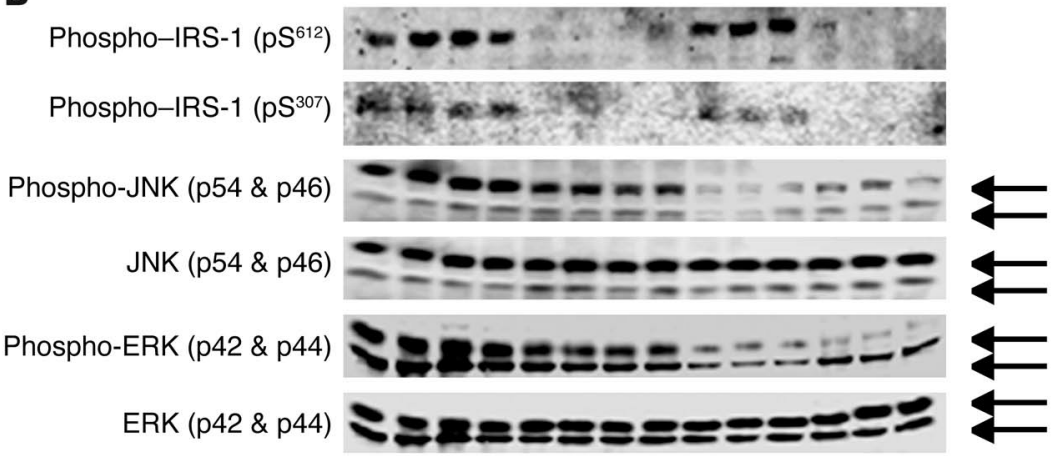

\section{Figure 9}

Alterations in insulin-signaling components in livers from $P d e 3 b-K O$ mice. Western blots of liver lysates (50 $\mathrm{\mu g}$ protein/lane) were performed as described in Methods. $n=4$ fed, 3 fasted mice per group. Data from an identical group of nonfasted $(n=4)$ and 6-hour-fasted $(n=3)$ WT and KO mice were similar. (A) Immunodetection with anti-phosphotyrosine (pY), anti-IRS-1, anti-insulin receptor (IR), antiphospho-PKB, anti-PKB, anti-phospho-FKHRL1 (pS253), anti-FKHRL1, anti-phospho-GSK-3 (pY216), and anti-GSK-3 antibodies. (B) Immunodetection with anti-phospho-IRS-1 (pS612), anti-phospho-IRS-1 (pS ${ }^{307}$ ), anti-phospho-JNK, anti-JNK, anti-phospho-ERK, and anti-ERK antibodies. with an important role for PDE3B in the regulation of cAMP pools that modulate lipolysis (7), i.p. injection of ISO or CL increased lipolysis (serum glycerol and FFA levels) to a greater extent in $\mathrm{KO}$ mice than in WT mice. CL also increased lipolysis to a greater extent in isolated $\mathrm{KO}$ adipocytes, and insulin inhibited lipolysis in WT, but not KO, adipocytes. Thus, an enhanced lipolytic "drive" could contribute to the development of insulin resistance. Consistent with our findings in $\mathrm{KO}$ mice, administration of milrinone, a PDE3 inhibitor, to intact rats increased lipolysis and insulin secretion and blocked insulin-induced suppression of EGP (35). Thus, absence or inhibition of PDE3B (e.g., via milrinone; ref. 35, 36) which may lead to altered insulin signaling and dysregulation of hepatic glucose output, could be associated with the development of insulin resistance (Table 1).

Although serum leptin levels were not consistently altered, adiponectin levels were significantly increased in $\mathrm{KO}$ mice. In addition to its ability to increase insulin sensitivity in peripheral tissues, especially liver $(27,29)$, adiponectin also exerts antiinflammatory actions and cardioprotective effects $(26,30)$ mediated by cAMP-dependent and -independent signaling pathways (30). It is conceivable that in $\mathrm{KO}$ mice, changes in adiponectin as well as the increase in insulin secretion in response to glucose, GLP-1, and putative catecholamine-induced adipokines/incre- tins (Figure 6) and the presence of smaller adipocytes and gonadal fat depots (Figure 3) represent mechanisms that maintain or improve sensitivity to insulin and/or prevent more marked insulin resistance and glucose intolerance in $\mathrm{KO}$ mice. Our current unpublished studies suggest that other compensatory mechanisms, especially more efficient or enhanced energy dissipation in $P d e 3 b-\mathrm{KO}$ mice and reduced expression of proinflammatory markers in $\mathrm{KO}$ epididymal adipose tissue, may also be partly responsible for these findings.

The results of our present studies with $\mathrm{KO}$ mice, which complement those of others $(5,10,19,20)$ as well as our earlier studies in transgenic mice (13) and cultured insulin-secreting cells and isolated pancreatic islets (12), have validated hypotheses concerning 2 important PDE3B functions, i.e., modulation of insulin's antilipolytic action and glucose- and cAMP-stimulated insulin secretion (7). In addition, our results suggest that PDE3B enzymes in adipose tissue, liver, and pancreatic $\beta$ cells play an important role in regulation of energy homeostasis.

\section{Methods}

Production of Pde3b-deficient mice. The Pde3b targeting vector (for construction of the Pde $3 b$ targeting vector, see Figure 1 and Supplemental Methods) was linearized with HindIII and electroporated into RW-4 (129/SvJ-derived) 
A

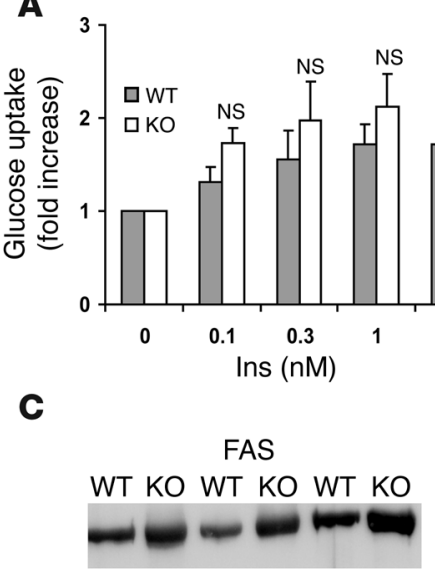

B

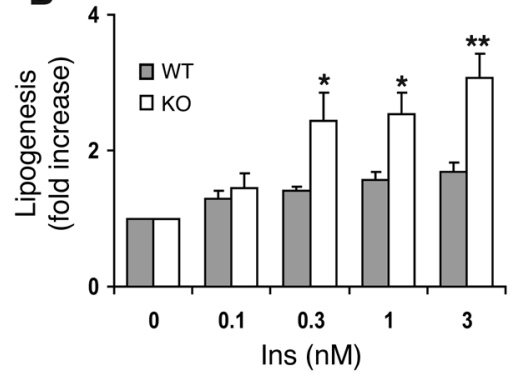

D

PKB

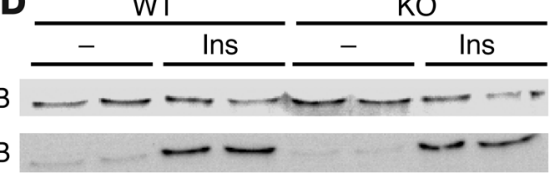

\section{Figure 10}

Effects of insulin on glucose uptake, lipogenesis, and activation of PKB in adipocytes from 3- to 3.5-month-old WT and Pde3b-KO mice. (A and

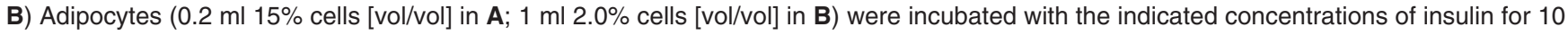
minutes $(\mathbf{A} ; n=3)$ and 3 hours $(\mathbf{B} ; n=5)$. Uptake of $2-\left[1-{ }^{3} \mathrm{H}\right]$-deoxyglucose $(\mathbf{A})$ and incorporation of $\mathbf{D}-\left[{ }^{3} \mathrm{H}\right]$-glucose into lipids $(\mathbf{B})$ were measured as described in Methods and expressed as fold increase relative to nonstimulated cells. In KO adipocytes, basal lipogenesis was $56 \% \pm 0.08 \%$ (mean \pm SEM; $P=0.0001$ ) that of WT adipocytes. Data (mean \pm SEM) are from 5 independent experiments, each of which used adipocytes pooled from 2-3 mice. ${ }^{\star} P<0.05$; ${ }^{\star \star} P<0.01$. (C) Western blot analysis of FAS from WT and KO mice (20 $\mu$ g protein/lane; $\left.n=3\right)$ using anti-FAS antibody. (D) Adipocytes (each batch consisted of adipocytes from 2 of a total 6 WT and $6 \mathrm{KO}$ mice) were incubated for 10 minutes with or without $1 \mathrm{nM}$ insulin. Adipocyte fractions, prepared as described in Methods, were subjected to Western blotting with antibody recognizing PKB phosphorylated on serine 473 and, after stripping, with anti-PKB antibody. One Western blot representative of 3 is shown. PKB/phosphorylated PKB bands from 6 WT and 6 KO mice were quantified.

ES cells (Human Genome Sciences). Positive ES cell clones, screened by Southern blot analysis and PCR, were microinjected into C57BL blastocysts and implanted into pseudopregnant females. Resulting chimeras were mated to Black Swiss mice to produce HE $\mathrm{F}_{1}$ progeny, which were backcrossed with the JAX 129/SvJ (pTyr ${ }^{c-c h} / \mathrm{pTyr}^{\mathrm{c}}$ ) substrain. Genotyping of generation $\mathrm{F}_{2}$ mice was performed with DNA from tail tips by Southern blots and PCR. Protocols for mouse generation and maintenance as well as all animal studies were approved by the NHLBI Animal Care and Use Committee.

Southern blots, Northern blots, genomic PCR, and real-time RT-PCR. All were performed as described in Supplemental Methods and Figure 1.

cAMP PDE assay. Further details are provided in Supplemental Methods. Samples were assayed as described previously (37). Protein concentration was determined by Protein Assay Reagent Kit (Pierce Biotechnology) with BSA as standard.

Tissue fractionation. Preparation of subcellular fractions and partial purification of liver PDE3A and PDE3B is described in Supplemental Methods, with results presented in Supplemental Figure 1.

Western blots. Details and commercial sources of antibodies are provided in Supplemental Methods. After SDS-PAGE, proteins were electrotransferred to PVDF membranes (Millipore). Chemiluminescent signals were developed with West Femto or Pico kits (Pierce Biotechnology), followed by detection by LAS-3000 or LAS-1000plus systems (FUJIFILM).

Adipocyte preparation, adipocyte size, lipolysis, glucose uptake, lipogenesis, and analysis of FAS and PKB. These processes are described in detail in Supplemental Methods. Adipocytes were isolated from epididymal fat pads by collagenase digestion (38) and were counted (39). Cell volumes were calculated from diameter measurements (at least 100 adipocytes of each preparation) made with a Zeiss LSM 5 confocal microscope. Total neutral lipid was measured gravimetrically and cell numbers were calculated (39). Lipolysis (glycerol accumulation) was measured using Trinder kits (Sigma-Aldrich) according to the manufacturer's instructions. We measured 2-deoxy-D-[1-3 $\mathrm{H}]$-glucose uptake and lipogenesis in isolated adipocytes as previously described $(8,40,41)$. Cytosolic fractions of adipocytes were used for Western blot analyses of FAS expression and $\mathrm{PKB} /$ phosphorylated PKB.

Liver TG content. Further details are provided in Supplemental Methods. After mice were euthanized, livers were immediately perfused in situ with PBS solution $(10 \mathrm{ml})$ via the portal vein to remove blood. Liver pieces $(100 \mathrm{mg}$ each) were homogenized in $1 \mathrm{ml}$ buffer $(0.5 \mathrm{M}$ Tris, $1 \%$ Triton X-100, $\mathrm{pH}$ 7.4). After extraction into chloroform/methanol (2:1), samples were dried and assayed for TG content using TG reagent (Trace/DMA; Thermo Electron Corp.), with triolein as standard and measuring absorbance at $540 \mathrm{~nm}$ according to the manufacturer's instructions.

Preparation of liver extracts from nonfasted and fasted mice. Further details are provided in Supplemental Methods. WT and KO male mice (5 months old; $n=4$ per group), nonfasted or fasted for 6 hours (started 1 hour after beginning a light cycle), were killed by $\mathrm{CO}_{2}$ asphyxiation, followed by cervical dislocation. Homogenates were centrifuged ( $1,000 \mathrm{~g}$ for $5 \mathrm{~min}-$ utes). Resulting supernatants (total extracts) were aliquoted and stored at $-80^{\circ} \mathrm{C}$ until future use.

Hepatic $c A M P$. Two hundred milligrams of frozen liver from nonfasted and fasted WT and KO mice ( $n=4$ per group) were immediately immersed into $1: 10(\mathrm{wt} / \mathrm{vol})$ ice-cold $0.1 \mathrm{~N} \mathrm{HCl}$ solution and homogenized (20 strokes with a Teflon pestle). After centrifugation $(20,000 \mathrm{~g}$ at $4{ }^{\circ} \mathrm{C}$ for 2 hours), supernatants were assayed for cAMP (cAMP assay kit; R\&D Systems).

Isolation of mouse islets. Further details are provided in Supplemental Methods. Pancreatic islets were isolated from 4-month-old WT and KO mice by a previously described collagenase digestion technique $(12,13)$. Groups of 3 islets were distributed in 96-well plates and incubated in $200 \mu$ l of modified Krebs-Ringer-HEPES buffer (10 mM HEPES, pH 7.2-7.4, $120 \mathrm{mM} \mathrm{NaCl}, 5 \mathrm{mM} \mathrm{KCl}, 2.5 \mathrm{mM} \mathrm{CaCl}_{2}, 1.2 \mathrm{mM} \mathrm{KH}_{2} \mathrm{PO}_{4}, 1.2 \mathrm{mM}$ $\mathrm{MgSO}_{4}, 5 \mathrm{mM} \mathrm{NaHCO}_{3}$, and $0.2 \% \mathrm{BSA}$ ) without or with glucose and/or 

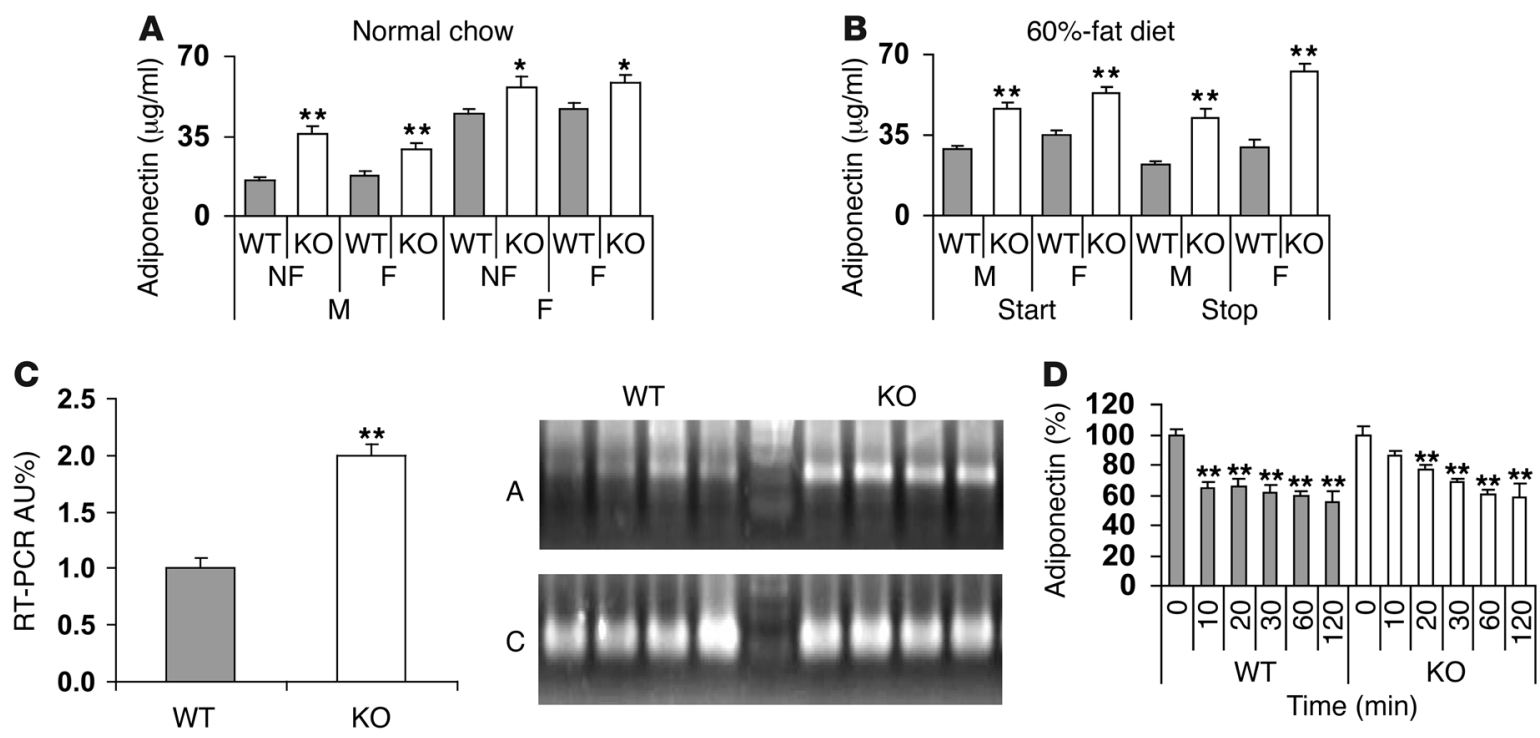

\section{Figure 11}

Adiponectin expression. (A and B) Serum adiponectin concentrations were quantified in WT and KO mice, either fed or after fasting for 20 hours, fed normal chow (A; 6 months of age) or at the start (at 2 months of age) and end (after 14 weeks) of a 60\%-fat diet (B). Data (mean \pm SEM; $n=6-9$ mice per group) were similar in 2 other experiments for A. (C) Adiponectin mRNA from epidydimal fat pads was amplified via real-time quantitative RT-PCR of total RNA as described in Supplemental Methods. Data (mean \pm SEM; $n=4$ mice per group) were similar in 2 other experiments. Inset: Agarose gel electrophoresis of adiponectin real-time RT-PCR products. A, adiponectin; C, cyclophilin A. Data from 1 other experiment were similar. (D) At the indicated times after i.p. injection $(10 \mathrm{ml} / \mathrm{kg})$ of CL $(1.0 \mathrm{mg} / \mathrm{kg})$ in PBS or PBS alone administered to $4-$ to 5 -month old WT and KO mice, serum adiponectin levels were measured. Data (mean \pm SEM) represent the percent change relative to basal values at time 0 ( $n=4-9$ mice per group). Basal adiponectin values were $22.2 \pm 0.7$ and $41.0 \pm 2.0 \mu \mathrm{g} / \mathrm{ml}$ in WT and KO, respectively. Note: Values at every time point following $\mathrm{CL}$ injection were significantly lower $(P<0.01)$ except at 10 minutes in $\mathrm{KO}$ mice in the case of adiponectin. Data from 1 other experiment were similar. ${ }^{*} P<0.05 ;{ }^{*} P<0.01$.

GLP-1 for 1 hour at $37^{\circ} \mathrm{C}$. Buffer was withdrawn for quantification of insulin (commercial RIA kits; Linco).

Immunohistochemistry. Further details are provided in Supplemental Methods. Pancreases were dissected, fixed overnight, rinsed thoroughly, and frozen on dry ice. Immunohistochemical analyses and measurements of islet size were performed as described previously (13).

Analysis of metabolites and hormones. For experiments in which blood glucose and/or serum glycerol, FFA, and insulin levels were measured following i.p. or i.v. injection of PBS alone or CL, ISO, insulin, or glucose in PBS, serum samples were prepared by centrifugation $\left(4^{\circ} \mathrm{C}\right)$ of blood collected from tail veins cut with a scalpel blade (after warming tails for 1 minute with a lamp) or from retroorbital sinuses. Insulin and leptin levels were assayed with ELISA kits from ALPCO Diagnostics and Crystal Chem Inc., respectively. FFA levels were measured enzymatically with the colorimetric Half-Micro Test (Roche Applied Science), and glycerol and TGs were measured with Trinder kits from Sigma-Aldrich or the enzymatic method of Wieland (42). Serum adiponectin was measured with a RIA kit (Linco), and blood glucose was measured in 1-2 drops of tail blood with the Bayer Glucometer Elite.

GTTs and ITTs. After overnight fasting, conscious mice were injected i.p. $(10 \mathrm{ml} / \mathrm{kg})$ with glucose $(2 \mathrm{~g} / \mathrm{kg})$ or insulin $(0.5 \mathrm{U} / \mathrm{kg})$ in PBS. At the indicated times (Figure 7), blood glucose was measured, and/or $0.2 \mathrm{ml}$ of tail blood was taken for measurement of serum FFA or insulin levels.

Hyperinsulinemic-englycemic clamps. Further details are provided in Supplemental Methods. The clamps, based on the procedure developed by Kim, Shulman, and collaborators $(43,44)$, were performed 4-6 days after catheter placement essentially as described by Chen et al. (45). Experiments, started after a 16 -hour overnight fast, used $\left[3-{ }^{3} \mathrm{H}\right]$ glucose and
2-deoxy-D- $\left[1-{ }^{14} \mathrm{C}\right]$-glucose (both from PerkinElmer) for the estimation of whole-body glucose fluxes and tissue glucose uptake, respectively. After 120 minutes of basal $\left[3-{ }^{3} \mathrm{H}\right]$ glucose infusion, hyperinsulinemic-euglycemic clamps were begun with a priming infusion of human insulin (300 $\mathrm{mIU} / \mathrm{kg}$ ) bolus over 3 minutes, followed by $15 \mathrm{pmol} / \mathrm{kg} / \mathrm{min}$ of Humulin R (Lilly), and $20 \%$ glucose was infused at a rate adjusted to keep plasma glucose at approximately $110 \mathrm{mg} / \mathrm{dl}$.

Statistics. Data are expressed as mean \pm SEM. All data presented with statistical analyses were analyzed using a 2-tailed Student's $t$ test (paired and unpaired) with Microsoft Excel 2003 with Data Analysis Toolpak (Microsoft). $P$ values less than 0.05 were considered to be significant.

\section{Acknowledgments}

We thank Martha Vaughan (NHLBI) for her support and critical reading of the manuscript as well as Ed Ginns (National Human Genome Research Institute, NIH) and Mary La Marca (National Institute of Mental Health, NIH) for assistance in generating the KO mice. This work was supported in part by grants to E. Degerman from the Swedish Medical Research Council (no. 3362), Novo Nordisk, the A. Påhlssons Foundation, and the Swedish Diabetes Association.

Received for publication February 25, 2005, and accepted in revised form October 10, 2006.

Address correspondence to: Young Hun Choi, PCCMB, NHLBI, NIH, 9000 Rockville Pike, Building 10, Room 5N307, Bethesda, Maryland 20892, USA. Phone: (301) 402-4774; Fax: (301) 402-1610; E-mail: Choiy@nhlbi.nih.gov. 
1. Collins, S., and Surwit, R.S. 2001. The $\beta$-adrenergic receptors and the control of adipose tissue metabolism and thermogenesis. Recent Prog. Horm. Res. 56:309-328.

2. Francis, S.H., Turko, I.V., and Corbin, J.D. 2001. Cyclic nucleotide phosphodiesterases - relating structure and function. Prog. Nucleic Acid Res. Mol. Biol. 65:1-52.

3. Manganiello, V.C., and Degerman, E. 2004. Cyclic nucleotide phosphodiesterases. In Encyclopedia of biological chemistry. W. Lennarz and M.D. Lane, editors. Elsevier Science Academic Press. San Diego, California, USA. 501-505.

4. Shakur, Y., et al. 2001. Regulation and function of the cyclic nucleotide phosphodiesterase (PDE3) gene family. Prog. Nucleic Acid Res. Mol. Biol. 66:241-277.

5. Zhao, A., Zhao, H., Teague, J., Fujimoto, W., and Beavo, J.A. 1997. Attenuation of insulin secretion by IGF-1 is mediated through activation of phosphodiesterase 3B. Proc. Natl. Acad. Sci. U. S. A 94:3223-3228.

6. Liu, H., and Maurice, D.H. 1998. Expression of cyclic GMP-inhibited phosphodiesterases $3 \mathrm{~A}$ and $3 \mathrm{~B}$ (PDE3A and PDE3B) in rat tissues: differential subcellular localization and regulated expression by cyclic AMP. Br. J. Pharmacol. 125:1501-1510.

7. Degerman, E., et al. 2003. Role for phosphodiesterase $3 \mathrm{~B}$ in regulation of lipolysis and insulin secretion. In Diabetes mellitus: a fundamental and clinical text. 3rd edition. D. LeRoith, S.I. Taylor, and J.M. Olefsky, editors. Lippincott-Raven Publishers. Philadelphia, Pennsylvania, USA. 373-381.

8. Zmuda-Trzebiatowska, E., Oknianska, A., Manganiello, V., and Degerman, E. 2005. Role of PDE3B in insulin-mediated glucose uptake, GLUT-4 translocation, and lipogenesis in primary rat adipocytes. Cell. Signal. 18:382-390.

9. Eriksson, J.W., Wesslau, C., and Smith, U. 1994. The cGMP-inhibitable phosphodiesterase modulates glucose transport activation by insulin. Biochim. Biophys. Acta. 1189:163-167.

10. Zhao, A.Z., Bornfeldt, K.E., and Beavo, J.A. 1998. Leptin inhibits insulin secretion by activation of phosphodiesterase 3B. J. Clin. Invest. 102:869-873.

11. Zhao, A.Z., et al. 2000. Leptin induces insulinlike signaling that antagonizes cAMP elevation by glucagon in hepatocytes. J. Biol. Chem. 275:11348-11354

12. Harndahl, L., et al. 2002. Important role of phosphodiesterase $3 \mathrm{~B}$ for the stimulatory action of cAMP on pancreatic $\beta$-cell exocytosis and release of insulin. J. Biol. Chem. 277:37446-37455.

13. Harndahl, L., et al. 2004. Beta-cell-targeted overexpression of phosphodiesterase $3 \mathrm{~B}$ in mice causes impaired insulin secretion, glucose intolerance and deranged islet morphology. J. Biol. Chem. 279:15214-15222.

14. Tang, Y., et al. 1999. Improvement in insulin resistance and the restoration of reduced phosphodiesterase $3 \mathrm{~B}$ gene expression by pioglitazone in adipose tissue of obese diabetic KKAy mice. Diabetes.
48:1830-1835

15. Tang, Y., et al. 2001. Adipocyte-specific reduction of phosphodiesterase 3B gene expression and its restoration by JTT-501 in the obese, diabetic KKAy mouse. Eur. J. Endocrinol. 145:93-99.

16. Tang, Y., et al. 2001. Phosphodiesterase 3B gene expression is enhanced in the liver but reduced in the adipose tissue of the obese insulin resistant $\mathrm{db} / \mathrm{db}$ mouse. Diabetes Res. Clin. Pract. 54:145-155.

17. Hasegawa, M., et al. 2002. Differential regulation of gene expression and insulin-induced activation of phosphodiesterase 3B in adipocytes of lean insulinresistant IRS-1(-/-) mice. Diabetes Res. Clin. Pract. 58:79-85.

18. Granneman, J.G., Lahners, K.N., and Chaudhry, A. 1991. Molecular cloning and expression of the rat $\beta_{3}$-adrenergic receptor. Mol. Pharmacol. 40:895-899.

19. El-Metwally, M., Shafiee-Nick, R., Pyne, N.J., and Furman, B.L. 1997. The effect of selective phosphodiesterase inhibitors on plasma insulin concentrations and insulin secretion in vitro in the rat. Eur.J. Pharmacol. 324:227-232.

20. Parker, J.C., Van Volkenburg, M.A., Nardone, N.A., Hargrove, D.M., and Andrews, K.M. 1997. Modulation of insulin secretion and glycemia by selective inhibitors of cAMP phosphodiesterase III. Biochem. Biophys. Res. Commun. 236:665-669.

21. Gavrilova, O., Marcus-Samuels, B., and Reitman, M.L. 2000. Lack of responses to a $\beta_{3}$-adrenergic agonist is lipoatrophic A-ZIP/F-1 mice. Diabetes. 49:1910-1916

22. Grujic, D., et al. 1997. $\beta_{3}$-adrenergic receptors on white and brown adipocytes mediate $\beta_{3}$-selective agonist-induced effects on energy expenditure, insulin secretion and food intake. J. Biol. Chem. 272:17686-17693.

23. Koo, S.H., et al. 2004. PGC-1 promotes insulin resistance in liver through PPAR $\alpha$-dependent induction of TRB-3. Nat. Med. 10:530-534.

24. Whiteman, E.L., Cho, H., and Birnbaum, M.J. 2002. Role of Akt/protein kinase B in metabolism. Trends Endocrinol. Metab. 13:444-451.

25. Klover, P., and Mooney, R.A. 2004. Hepatocytes: critical for glucose homeostasis. Int. J. Biochem. Cell Biol. 36:753-758

26. Scherer, P.E. 2006. Adipose tissue: from lipid storage compartment to endocrine organ. Diabetes. 55:1537-1545.

27. Berg, A.H., Combs, T.P., Du, X., Brownlee, M., and Scherer, P. 2001. The adipocyte secreted protein Acrp30 enhances hepatic insulin action. Nat. Med. 7:947-953.

28. Arner, P. 2003. The adipocyte in insulin resistance: key molecules and the impact of thiazolidenediones. Trends Endocrinol. Metab. 14:137-145

29. Yamauchi, T., et al. 2002. Adiponectin stimulates glucose utilization and fatty acid oxidation by activating AMP-activated protein kinase. Nat. Med. 8:1288-1295.

30. Ouedraogo, R., et al. 2006. Adiponectin suppression of high glucose-induced reactive oxygen species in vascular endothelial cells: evidence for involvement of a cAMP signaling pathway. Diabetes. 55:1840-1846.

31. Den Boer, M., Voshol, P.J., Kuipers, F., Havekes, L.M., and Romijin, J.A. 2004. Hepatic steatosis: a mediator of the metabolic syndrome. Lessons from animal models. Arterioscler. Thromb. Vasc. Biol. 24:644-649.

32. Seppala-Lindroos, A., et al. 2002. Fat accumulation in the liver is associated with defects in insulin suppression of glucose production and serum free fatty acids independent of obesity in normal men. J. Clin. Endocrinol. Metab. 87:3023-3028.

33. Adams, L.A., Angulo, P., and Lindor, K.D. 2005. Nonalcoholic fatty liver disease. CMAJ. 172:899-905.

34. Boden, G. 1997. Role of fatty acids in the pathogenesis of insulin resistance and NIDDM. Diabetes. 46:3-10.

35. Cheung, P., Yang, G., and Boden, G. 2003. Milrinone, a selective PDE3 inhibitor, stimulates lipolysis, endogenous glucose production and insulin secretion. Metabolism. 52:1496-1500.

36. Degerman, E., Manganiello, V., Holst, J.J., and Ahren, B. 2004. Milrinone efficiently potentiates insulin secretion induced by orally, but not intravenously, administered glucose in C57BL6J mice. Eur. J. Pharmacol. 498:319-323.

37. Kincaid, R.L., and Manganiello, V.C. 1988. Assay of cyclic nucleotide phosphodiesterase using radiolabeled and fluorescent substrates. Methods Enzymol. 159:457-470.

38. Honnor, R.C., Dhillon, G.S., and Londos, C. 1985. cAMP-dependent protein kinase and lipolysis in rat adipocytes. I. Cell preparation, manipulation, and predictability in behavior. J. Biol. Chem. 260:15122-15129.

39. Fine, J.B., and Di Girolamo, M. 1997. A simple method to predict cellular density in adipocyte metabolic incubations. Int. J. Obes. Relat. Metab. Disord. 21:764-768.

40. Ramlal, T., Sarabia, V., Bilan, P.J., and Klip, A. 1988. Insulin-mediated translocation of glucose transporters from intracellular membranes to plasma membranes: sole mechanism of stimulation of glucose transport in L6 muscle cells. Biochem. Biophys. Res. Commun. 157:1329-1335.

41. Moody, A.J., Stan, M.A., Stan, M., and Gliemann, J. 1974. A simple free fat cell bioassay for insulin. Horm. Metab. Res. 6:12-16.

42. Wieland, O. 1957. Enzymic method for the determination of glycerin. Biochem. Z. 329:313-319.

43. Kim, J.K., et al. 2000. Redistribution of substrates to adipose tissue promotes obesity in mice with selective insulin resistance in muscle. J. Clin. Invest. 105:1791-1797.

44. Haluzik, M., et al. 2002. Adrenalectomy improves diabetes in A-ZIP/F-1 lipoatrophic mice by increasing both liver and muscle insulin sensitivity. Diabetes. 51:2113-2118.

45. Chen, M., et al. 2004. Increased insulin sensitivity in paternal Gnas KO mice is associated with increased lipid clearance. Endocrinology. 145:4094-4102. 